\title{
Hydrogen sulfide as a vasculoprotective factor
}

\author{
Eloise Streeter, Hooi H Ng and Joanne L Hart ${ }^{*}$
}

\begin{abstract}
Hydrogen sulfide is a novel mediator with the unique properties of a gasotransmitter and many and varied physiological effects. Included in these effects are a number of cardiovascular effects that are proving beneficial to vascular health. Specifically, $\mathrm{H}_{2} \mathrm{~S}$ can elicit vasorelaxation, prevention of inflammation and leukocyte adhesion, anti-proliferative effects and anti-thrombotic effects. Additionally, $\mathrm{H}_{2} \mathrm{~S}$ is a chemical reductant and nucleophile that is capable of inhibiting the production of reactive oxygen species, scavenging and neutralising reactive oxygen species and boosting the efficacy of endogenous anti-oxidant molecules. These result in resistance to oxidative stress, protection of vascular endothelial function and maintenance of blood flow and organ perfusion. $\mathrm{H}_{2} \mathrm{~S}$ has been shown to be protective in hypertension, atherosclerosis and under conditions of vascular oxidative stress, and deficiency of endogenous $\mathrm{H}_{2} \mathrm{~S}$ production is linked to cardiovascular disease states. Taken together, these effects suggest that $\mathrm{H}_{2} \mathrm{~S}$ has a physiological role as a vasculoprotective factor and that exogenous $\mathrm{H}_{2} \mathrm{~S}$ donors may be useful therapeutic agents. This review article will discuss the vascular effects and anti-oxidant properties of $\mathrm{H}_{2} \mathrm{~S}$ as well as examine the protective role of $\mathrm{H}_{2} \mathrm{~S}$ in some important vascular disease states.
\end{abstract}

Keywords: Hydrogen sulfide, Vasculoprotective, Atherosclerosis oxidative stress

\section{Introduction}

Hydrogen sulfide is now a recognised gaseous mediator and induces many and varied biological effects [1]. Several cardiovascular actions of $\mathrm{H}_{2} \mathrm{~S}$ have been described, including vasorelaxation, prevention of inflammation and leukocyte adhesion, anti-proliferative effects, antithrombotic effects, resistance to oxidative stress and protection against ischemia-reperfusion injury. These result in protection of endothelial function, resistance to vascular remodelling and maintenance of blood flow and organ perfusion. Taken together, these effects suggest that $\mathrm{H}_{2} \mathrm{~S}$ has a physiological role as a vasculoprotective factor. This review examines the evidence that $\mathrm{H}_{2} \mathrm{~S}$ is an important vascular regulator and protectant.

\section{$\mathrm{H}_{2} \mathrm{~S}$ production, storage and metabolism}

$\mathrm{H}_{2} \mathrm{~S}$ is produced endogenously via the metabolism of cysteine and/or homocysteine [2], by the enzymes cystathionine$\beta$-synthase (CBS, EC 4.2.1.22) [3] and cystathionine- $\gamma$-lyase (CSE, EC 4.4.1.1) [4]. 3-mercaptopyruvate sulfurtransferase (3-MST, EC 2.8.1.2) can also generate $\mathrm{H}_{2} \mathrm{~S}$ acting in concert with cysteine aminotransferase (EC 2.6.1.75) to

\footnotetext{
* Correspondence: Joanne.hart@rmit.edu.au

School of Medical Sciences and Health Innovations Research Institute (HIRi), RMIT University, PO Box 70, Bundoora, Vic 3083, Australia
}

metabolise cysteine, generating pyruvate and $\mathrm{H}_{2} \mathrm{~S}$ [5]. CBS is a major contributor to $\mathrm{H}_{2} \mathrm{~S}$ production in the brain, whilst CSE levels predominate in most peripheral tissues. 3-MST appears to contribute to $\mathrm{H}_{2} \mathrm{~S}$ production in both the periphery and central nervous system $[5,6]$. In the vascular system CSE is primarily expressed in vascular smooth muscle cells but there is also evidence that it is expressed in the endothelium $[7,8]$.

$\mathrm{H}_{2} \mathrm{~S}$ is metabolized by mitochondrial oxidative modification that converts sulfide into thiosulfate, which is converted further into sulfite and finally sulfate, which is the major end product of $\mathrm{H}_{2} \mathrm{~S}$ metabolism [9]. $\mathrm{H}_{2} \mathrm{~S}$ consumption in the presence of $\mathrm{O}_{2}$ is high [10], thus $\mathrm{H}_{2} \mathrm{~S}$ production is offset by rapid clearance, resulting in low basal levels of $\mathrm{H}_{2} \mathrm{~S}$. In addition to high clearance $\mathrm{H}_{2} \mathrm{~S}$ may also be stored as acid-labile sulphur [11] or bound sulfane sulphur within cells [12]. The metabolic turnover of $\mathrm{H}_{2} \mathrm{~S}$ and concentrations of the gas generated in vivo during cell stimulation are yet to be fully elucidated and will be an area of importance in $\mathrm{H}_{2} \mathrm{~S}$ biology future research.

\section{Gasotransmitter and chemical properties}

Gaseous mediators or gasotransmitters are a relatively new class of signalling molecules, These gases share 
many features in their production and action but differ from classical signalling molecules. Advantages of gases as signalling molecules include their small size which allows easy access to a variety of target sites that would not be accessible by larger molecules. They easily cross membranes, are labile with short half-lives and are made on demand. They are not stored in their native form as they can't be constrained by vesicles and need to be bound for storage or rely upon de novo synthesis. They can have endocrine, paracrine, autocrine or even intracrine effects. It is also interesting that all the molecules confirmed as gasotransmitters (nitric oxide (NO), carbon monoxide $(\mathrm{CO}), \mathrm{H}_{2} \mathrm{~S}$ ) were all considered only as toxic molecules until their endogenous production and effects were determined.

About $80 \%$ of $\mathrm{H}_{2} \mathrm{~S}$ molecules dissociate into hydrosulfide anion ( $\mathrm{HS}^{-}$) at physiological $\mathrm{pH} 7.4$ in plasma and extracellular fluids [13]. $\mathrm{HS}^{-}$is a potent one-electron chemical reductant and nucleophile that is capable of scavenging free radicals by single electron or hydrogen atom transfer $[14,15]$ Thus, $\mathrm{H}_{2} \mathrm{~S}$ should readily scavenge reactive nitrogen species (RNS) and reactive oxygen species (ROS) [16]. It is also now established that $\mathrm{H}_{2} \mathrm{~S}$ can signal via sulhydration of proteins [17], and much research is ongoing in this area.

\section{$\mathrm{H}_{2} \mathrm{~S}$ effects on blood vessels}

Endothelium derived substances that cause vasodilatation (eg NO, prostacyclin) are anti-proliferative and anti-thrombotic while constrictor factors (endothelin-1, thromboxane $\mathrm{A}_{2}$ ) are proliferative and pro-coagulant. Thus the vasodilators can be considered vasculoprotective, as they protect and promote blood flow and a balance of endothelium-derived relaxing and contracting factors is required for a healthy vascular function [18]. $\mathrm{H}_{2} \mathrm{~S}$ is produced in blood vessels by both endothelial cells and vascular smooth muscle has these same vasculoprotective properties (Figure 1). These are further discussed below.

\section{Vasorelaxation elicited by $\mathrm{H}_{2} \mathrm{~S}$}

$\mathrm{H}_{2} \mathrm{~S}$ induced vasorelaxation in peripheral vessels may be mediated by various mechanisms, including opening of potassium channels, blockade of voltage-gated $\mathrm{Ca}^{2+}$ channels, enhanced production or activity endothelial derived factors, such as $\mathrm{NO}, \mathrm{PGI}_{2}$ and EDHF and decreased $\mathrm{pH}_{\mathrm{i}}$. The vasorelaxant effect occurs in both large conduit [19-22] and small resistance-like blood vessels [7,23,24] and is physiologically relevant since an inhibition of CSE in isolated mouse aorta in vitro causes significant vascular contraction [19] and most importantly, mice deficient in CSE are hypertensive and have endothelial dysfunction [8].

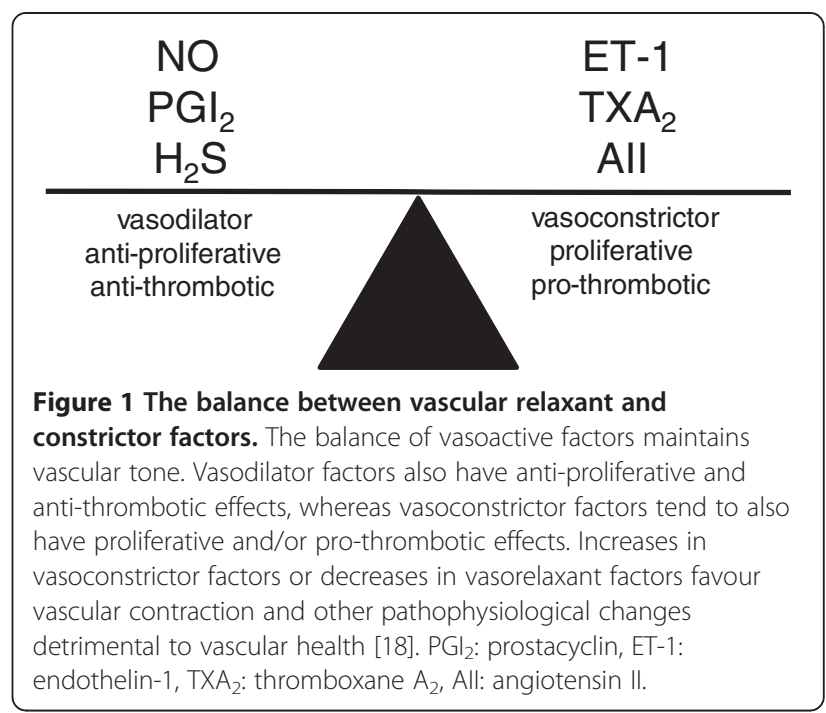

\section{Platelet inhibition}

Limited data is available on the action of $\mathrm{H}_{2} \mathrm{~S}$ on platelets, although it has been reported that $\mathrm{H}_{2} \mathrm{~S}$ can decrease platelet aggregation [25]. A recent in vitro study showed that platelet adhesion to collagen and fibrinogen, the first step in platelet activation and aggregation, was significantly reduced by nanomolar concentrations of NaHS. Additionally, platelet superoxide production was also inhibited although the mechanism of this effect was not examined [26]. Whilst platelet adhesion and aggregation are important for vascular haemostatis in trauma, they are undesirable under conditions of vascular inflammation and atherosclerosis, so further investigation into the role of $\mathrm{H}_{2} \mathrm{~S}$ in platelet function is warranted.

\section{$\mathrm{H}_{2} \mathrm{~S}$ as an anti-oxidant in the vasculature}

Reactive oxygen species (ROS) can be divided into free radicals, such as superoxide $\left(\mathrm{O}_{2}{ }^{-{ }^{-}}\right)$and hydroxyl $\left(\mathrm{OH}^{\circ}\right)$; non-radicals, such as hydrogen peroxide $\left(\mathrm{H}_{2} \mathrm{O}_{2}\right)$; and reactive nitrogen species, such as $\mathrm{NO}$ (technically, $\mathrm{NO}$, since it is a radical gas, with an unpaired electron) and peroxynitrite $\left(\mathrm{ONOO}^{-}\right)$. In vascular cells, there are multiple sources for the generation of ROS, including mitochondria, cyclooxygenases and NADPH oxidases, xanthine oxidase, cyclo-oxygenase [27]. In mammalian tissues, reactive oxygen species (ROS) such as superoxide $\left(\mathrm{O}_{2}^{*-}\right)$ are produced under both pathological and physiological conditions. They are essential for the immunological defence mechanism of phagocytes, however, overproduction of ROS has detrimental effects on tissues including the vasculature. Excess ROS levels or oxidative stress are implicated in the pathology and progression of cardiovascular disease [28]. Excess levels of ROS can compromise the antioxidant defence mechanism of the cells and react with cellular macromolecules such as lipids, proteins, membrane bound polyunsaturated fatty acids and DNA leading 
to irreversible cellular damage [29]. Furthermore, perhaps the best characterized mechanism by which oxidative stress can cause dysfunction and damage to vascular cells is via the scavenging of vasoprotective nitric oxide by $\mathrm{O}_{2}^{*-}$ leading to a reduction its biological half-life [30].

Superoxide is the parent ROS molecule in all cells. It can be generated in vascular cells by NADPH oxidases (or "Nox oxidases"), uncoupled endothelial NO synthase (eNOS), the mitochondrial enzyme complexes, cytochrome P450 and xanthine oxidase [27]. The Nox oxidases are the only enzymes discovered to date that have the primary function of generating superoxide (Nox1-3) and hydrogen peroxide (Nox4). This family of enzymes compromises two membrane-bound subunits, the Nox catalytic subunit and p22phox as well as various combinations of cytoplasmic subunits [31]. In the aorta at least 3 isoforms of Nox oxidase are expressed, Nox1-, Nox2and Nox4-containing Nox oxidases. Importantly, ROS are generated at low levels in cerebral vessels and act there as signalling molecules involved in vascular regulation [32]. Excessive production of ROS, in particular superoxide $\left(\mathrm{O}_{2}^{*-}\right)$ from Nox oxidases is implicated as a key mediator of endothelial dysfunction (loss of $\mathrm{NO}$ bioavailability) associated with many cardiovascular diseases, including atherosclerosis, diabetic vascular disease and hypertension [33].

\section{$\mathrm{H}_{2} \mathrm{~S}$ as a ROS scavenger}

$\mathrm{H}_{2} \mathrm{~S}$ is a potent one-electron chemical reductant and nucleophile that is theoretically capable of scavenging free radicals by single electron or hydrogen atom transfer [14]. Thus, $\mathrm{H}_{2} \mathrm{~S}$ may participate in many reactions [34] and is reported to readily scavenge reactive oxygen and nitrogen species such as peroxynitrite [35], superoxide [36], hydrogen peroxide [37], hypochlorous acid [38] and lipid hydroperoxides [14]. However the kinetics, reactivity and mechanism of $\mathrm{H}_{2} \mathrm{~S} / \mathrm{HS}^{-}$interactions with ROS are poorly understood under physiological conditions [14]. $\mathrm{H}_{2} \mathrm{~S}$ has been reported to inhibit superoxide production in human endothelial cells [39] and vascular smooth muscle cells [40] by reducing Nox oxidase expression and activity. However it is not known if this activity is physiologically relevant, or whether $\mathrm{H}_{2} \mathrm{~S}$ can protect against oxidative-stress driven vascular dysfunction. In addition, $\mathrm{H}_{2} \mathrm{~S}$ is reported to increase glutathione levels and bolster endogenous anti-oxidant defences [41]. Collectively, these findings suggest that this molecule may be a useful vasoprotective agent.

\section{$\mathrm{H}_{2} \mathrm{~S}$ as an inhibitor of ROS formation}

$\mathrm{H}_{2} \mathrm{~S}$ has also been shown to be important in regulating mitochondrial function [42] and can reduce mitochondrial ROS formation [43]. Hyperglycaemia induced overproduction of ROS was reversed with $\mathrm{H}_{2} \mathrm{~S}$ treatment and furthermore, endogenously produced $\mathrm{H}_{2} \mathrm{~S}$ acts to protect endothelial function from hyperglycaemic oxidative stress [44]. NaHS protects rat aortic smooth muscle cells from homocysteine-induced cytotoxicity and reactive oxygen species generation, and furthermore NaHS-induced protective effects were synergistic with endogenous anti-oxidants [36]. This study suggests that $\mathrm{H}_{2} \mathrm{~S}$ is capable of reducing production of $\mathrm{H}_{2} \mathrm{O}_{2}, \mathrm{ONOO}^{-}$ and $\mathrm{O}_{2}^{--}$in a time and concentration dependent manner. The mechanism of this effect was not established, however $\mathrm{H}_{2} \mathrm{~S}$ at nanomolar concentrations has been reported to inhibit superoxide formation in human endothelial cells [39] and vascular smooth muscle cells [40] by reducing Nox oxidase expression and activity.

\section{$\mathrm{H}_{2} \mathrm{~S}$ effects on endogenous anti-oxidants}

$\mathrm{NaHS}$ has been shown to protect neurons from oxidative stress by boosting glutathione levels [41] and others have also shown that NaHS increases the activity of endogenous anti-oxidants such as superoxide dismutase, glutathione perioxidase and glutathione reductase [36,43,45,46]. There is now increasing evidence that $\mathrm{H}_{2} \mathrm{~S}$ has a role in regulating the nuclear factor erthyroid 2 (NF-E2)-related factor 2 (Nrf2) pathway. Nrf2 is a key transcription regulator of inducible cell defence. In the presence of electrophiles and/or reactive oxygen species, Nrf2 accumulates, translocates to the cell nucleus and binds with antioxidant response elements (AREs). These are located within the promoter regions of an array of cell defence genes, regulating both basal and inducible expression of anti-oxidant proteins, detoxification enzymes and other stress response proteins [47].

Recent studies have shown that $\mathrm{H}_{2} \mathrm{~S}$ donor treatment can induce Nrf2 expression [48,49] enhance Nrf2 translocation to the nucleus [50,51] and activate Nrf2 signalling [52], resulting in reduced oxidative stress and cardioprotection. The mechanism of the upregulation of $\mathrm{Nrf2}$ by $\mathrm{H}_{2} \mathrm{~S}$ is under investigation with recent reports that $\mathrm{H}_{2} \mathrm{~S}$ inactivates the negative regulator of Nrf2, Keap1 [53,54] resulting in the Nrf2 mediated induction of cytoprotective genes.

Taken together, recent reports suggest that $\mathrm{H}_{2} \mathrm{~S}$ is capable of inhibiting the production of ROS, scavenging and neutralising ROS and boosting the efficacy of endogenous anti-oxidant molecules (Figure 2). The net effect is protection of vascular function and future work is needed to further examine the potential therapeutic benefits of the anti-oxidant effects of $\mathrm{H}_{2} \mathrm{~S}$.

\section{Studies in vascular disease states showing vasculoprotective effects of $\mathrm{H}_{2} \mathrm{~S}$ Hypertension}

Hypotensive effects of $\mathrm{H}_{2} \mathrm{~S}$ were first reported when administration of $\mathrm{H}_{2} \mathrm{~S}$ donors in vivo to anaesthetised rats was found to induce a transient hypotensive effect [55]. 


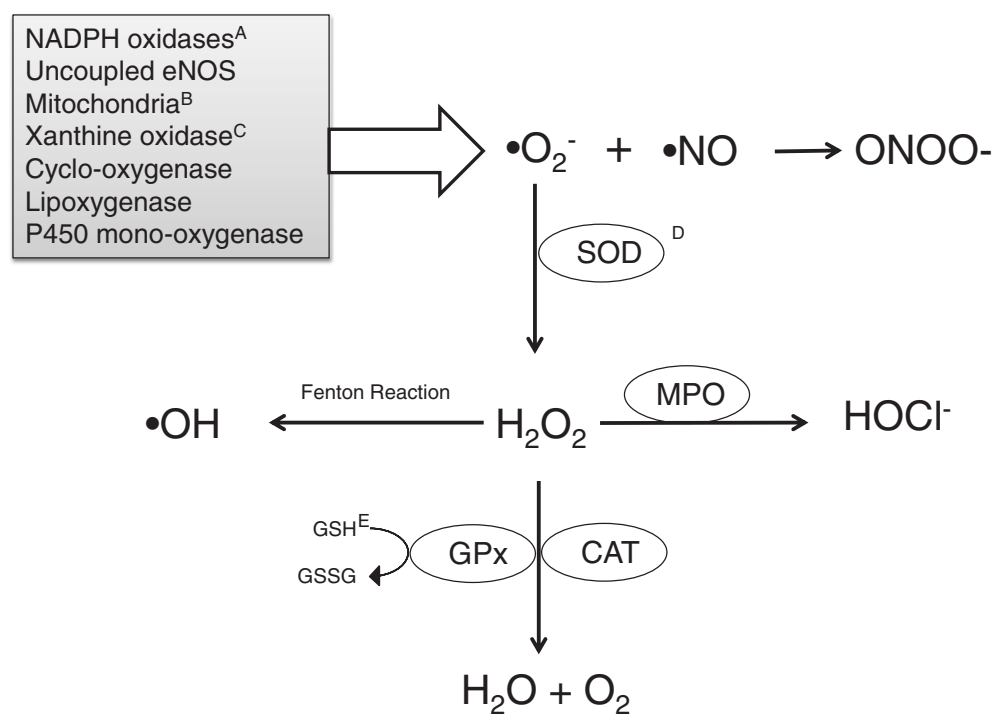

Figure 2 Sources of vascular reactive oxygen species and potential protective effects of $\mathrm{H}_{2} \mathrm{~S}$. Schema showing the major vascular sources of superoxide, the parent reactive oxygen species. $\mathrm{H}_{2} \mathrm{~S}$ has been shown to inhibit $\mathbf{A}$. NADPH oxidase activity and expression [39,40], B. mitochondrial ROS production [43], and possibly $\mathbf{C}$. xanthine oxidase activity [74]. Additionally, $\mathrm{H}_{2} \mathrm{~S}$ has been reported to scavenge ROS [35-38] and also promote the actions of D. SOD [43] and E. GSH [41]. SOD: superoxide dismutase, MPO: myeloperoxidase, CAT: catalase, GPx: glutathione peroxidase, GSH: reduced glutathione, GSSG, oxidised glutathione.

The CSE-L-cysteine pathway is downregulated in spontaneously hypertensive rats and treating them with a $\mathrm{H}_{2} \mathrm{~S}$ donor is protective, reducing blood pressure and vascular remodelling [56]. The most compelling evidence for the importance of $\mathrm{H}_{2} \mathrm{~S}$ in blood pressure regulation is that mice deficient in CSE develop endothelial dysfunction and hypertension within 8 weeks of birth and that $\mathrm{H}_{2} \mathrm{~S}$ replacement decreases systolic blood pressure in both $\mathrm{CSE}^{-/-}$and $\mathrm{CSE}^{+/-}$mice [8]. $\mathrm{H}_{2} \mathrm{~S}$ is also reported to regulate plasma renin levels [57] and inhibit angiotensin converting enzyme (ACE) activity in endothelial cells [58]. Inhibitory effects on ACE could also contribute to the anti-remodelling effects, which involve $\mathrm{H}_{2} \mathrm{~S}$ inhibition of collagen synthesis and smooth muscle proliferation in spontaneously hypertensive rats [59].

\section{Angiogenesis}

$\mathrm{H}_{2} \mathrm{~S}$ in implicated in the control of angiogenesis as NaHS treatment caused endothelial cell proliferation, adhesion, migration and tubule formation [60,61], with further work showing that vascular endothelial growth factor (VEGF) induced angiogenesis is mediated via $\mathrm{H}_{2} \mathrm{~S}$ [61] and that $\mathrm{H}_{2} \mathrm{~S}$ treatment in vivo increases collateral vessel growth, capillary density and blood flow in a hindlimb ischaemia model [62].

\section{Atherosclerosis}

Atherosclerosis is a chronic immune-inflammatory, fibroproliferative disease caused by lipid accumulation, affecting large and medium-sized arteries [63] Atherosclerosis is the most common underlying cause in the development of coronary artery disease. It has a multifactorial pathogenesis, involving vascular inflammation, recruitment and infiltration of monocytes, differentiation of monocytes to foam cells. This leads to increased reactive oxygen species generation resulting in an impairment of vascular endothelial function, by reducing NO bioavailability [64]. Further accumulation of foam cells and vascular smooth muscle cell proliferation lead to the formation of vascular lesions or plaques, which disrupt blood flow and reduce vessel compliance. A number of studies have indicated that $\mathrm{H}_{2} \mathrm{~S}$ has many properties that may lead to the inhibition of atherogenesis (for review see [65]).

$\mathrm{H}_{2} \mathrm{~S}$ donors have been shown to reduce inflammatory mediators, an effect that is dose-dependent and also influenced by delivery of $\mathrm{H}_{2} \mathrm{~S}$. Rapid delivery via NaHS is more likely to induce pro-inflammatory effects, whereas a more controlled delivery via the newer $\mathrm{H}_{2} \mathrm{~S}$ donor GYY4137 produces mostly anti-inflammatory effects [66]. $\mathrm{H}_{2} \mathrm{~S}$ treatment leads to decreased chemokine signalling [67] due to $\mathrm{H}_{2} \mathrm{~S}$-donor dependent downregulation of macrophage CX3CR1 receptor expression, and CX3CR1mediated chemotaxis [67]. NaHS inhibited leukocyte adhesion in mesenteric venules, and importantly, inhibiting CSE enhanced leukocyte adherence and infiltration [68]. $\mathrm{NaHS}$ treatment reduced ICAM-1 levels in $\mathrm{ApoE}^{-1-}$ mice [69]. This adhesion molecule participates in adhesion strengthening, monocyte spreading and transendothelial migration thus contributes to the infiltration of inflammatory cells into the vessel wall [70]. 


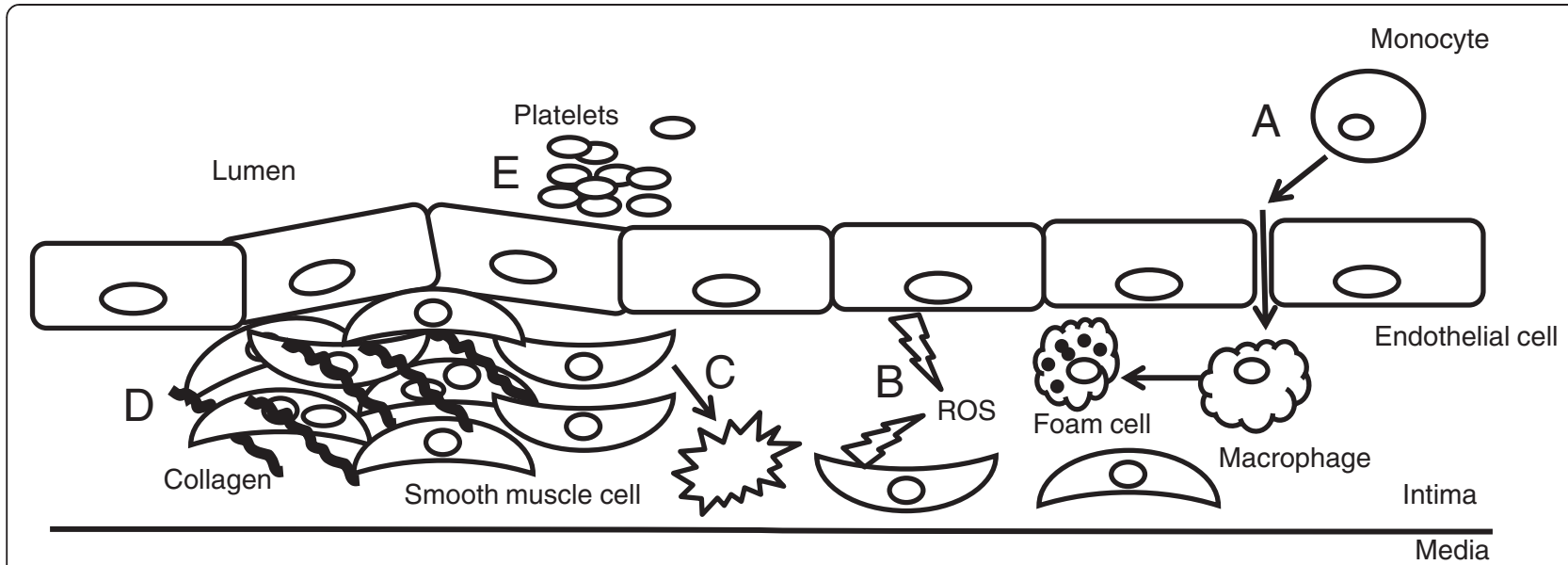

Figure 3 Potential sites of vasculoprotective effects of $\mathbf{H}_{2} \mathrm{~S}$. Cartoon depicting a cross section of the vascular wall showing the endothelium, intima containing smooth muscle cells overlaying the vascular media. A. $\mathrm{H}_{2} \mathrm{~S}$ has been shown to decrease leukocyte adhesion and migration [60] and differentiation to foam cells [64]. B. $\mathrm{H}_{2} \mathrm{~S}$ can inhibit the production of ROS [39,40] as well as scavenge ROS [35-38], protecting endothelial function. $\mathrm{C}_{2} \mathrm{~S}$ prevents proliferation [66] and promotes apoptosis of vascular smooth muscle cells [67] $\mathbf{D}$. $\mathrm{H}_{2} \mathrm{~S}$ prevents collagen deposition [51] and neo-intima formation [65]. $\mathbf{E ~} \mathrm{H}_{2} \mathrm{~S}$ can inhibit platelet adhesion [26] and aggregation [25].

Once leukocytes have traversed the vessel wall the next stage in atherogenesis is foam cell formation. $\mathrm{H}_{2} \mathrm{~S}$ has been shown to inhibit hypochlorite induced atherogenic modification of purified LDL in vitro [71] and further studies have revealed that NaHS treatment inhibits macrophage expression of scavenger receptors (CD36 and scavenger receptor A) and acyl-coenzyme A:cholesterol acyltransferase-1, key proteins required for uptake of oxidized lipoproteins and subsequent cholesterol esterification required for foam cell production [72].

Administration of $\mathrm{H}_{2} \mathrm{~S}$ donors lead to a number of effects on vessel remodelling. In one study, CSE expression was reduced, and endogenous $\mathrm{H}_{2} \mathrm{~S}$ production decreased in blood vessels with balloon-injury induced neointima. The neointima formation was attenuated in animals treated with $\mathrm{NaHS}$ [73]. $\mathrm{H}_{2} \mathrm{~S}$ is known to cause inhibition of proliferation [74], and induction of apoptosis [75] in human aortic vascular smooth muscle cells, and reduce collagen deposition [59]. CSE over-expression in human embryonic kidney cells inhibits proliferation [76] and importantly, a recent study showed that CSE-deficient mice have increased neointima formation, that was reversed with $\mathrm{NaHS}$ treatment [77].

$\mathrm{NaHS}$ treatment of $\mathrm{ApoE}^{-/-}$mice on a high fat diet reduced atherosclerotic lesion area [69]. NaHS treatment has been shown to inhibit vascular smooth muscle cell calcification in both cell culture [78] and in a rat model of vascular calcification [79]. Additionally, NaHS treatment in fat fed $\mathrm{ApoE}^{-/-}$mice improved endothelial function and reduced vascular oxidative stress. Plasma $\mathrm{H}_{2} \mathrm{~S}$ levels are correlated with higher HDL and adiponectin levels and lower triglycerides and LDL/HDL ratio [80] in healthy human subjects, suggesting that increasing sulfide consumption may have cardiovascular benefits. Overall $\mathrm{H}_{2} \mathrm{~S}$ has been shown to impede atherogenesis at all stages of the disease process (Figure 3). Taken together these effects all point towards an atheroprotective effect of endogenous $\mathrm{H}_{2} \mathrm{~S}$, that is elicited by endogenous $\mathrm{H}_{2} \mathrm{~S}$ and that exogenous $\mathrm{H}_{2} \mathrm{~S}$ application may be a useful therapeutic strategy to prevent vascular remodelling.

\section{Changes in expression of CSE in disease states}

Altered expression of CSE and reduced endogenous $\mathrm{H}_{2} \mathrm{~S}$ are observed in inflammation [68], atherosclerosis [69], diabetes [81], hypertension [56] and treatment with $\mathrm{H}_{2} \mathrm{~S}$ donors has been repeatedly shown to be beneficial. The inverse relationship between plasma $\mathrm{H}_{2} \mathrm{~S}$ levels and vascular disease strongly suggests a role for endogenous $\mathrm{H}_{2} \mathrm{~S}$ in maintaining normal vascular functions.

\section{Conclusions}

The field of $\mathrm{H}_{2} \mathrm{~S}$ biology is new and exciting with regular reports of new developments in the literature. It is clearly an important mediator in the vascular system, contributing to vascular regulation and protection of cells from oxidative stress and the vascular injury that result from this and leads to vascular dysfunction. There is good evidence that $\mathrm{H}_{2} \mathrm{~S}$ donor treatment has potential as a vasculoprotective agent for the prevention and reversal of cell damage that is implicit in many vascular disease states.

\section{Abbreviations}

CBS: Cystathionine- $\beta$-synthase; CSE: Cystathionine-y-lyase; MST: 3mercaptopyruvate sulfurtransferase; $\mathrm{PGI}_{2}$ : Prostacyclin; ET-1: Endothelin-1; All: Angiotensin II; EDHF: Endothelium-derived hyperpolarising factor; NADPH: Nicotinamide adenine dinucleotide phosphate; Nox: NADPH 
oxidase; ROS: Reactive oxygen species; SOD: Superoxide dismutase; CAT: Catalase; MPO: Myeloperoxidase; GPx: Glutathione peroxidase; GSH: Reduced glutathione; GSSG: Oxidized glutathione; ACE: Angiotensin converting enzyme; VEGF: Vascular endothelial growth factor; LDL: Low density lipoprotein; HDL: High density lipoprotein.

\section{Competing interests}

The authors declare that they have no competing interests.

\section{Authors' contributions}

$\mathrm{JH}, \mathrm{HN}$ and ES wrote the manuscript. All authors have read and approved the final manuscript.

Received: 11 February 2013 Accepted: 24 April 2013

Published: 29 April 2013

\section{References}

1. Wang R: Physiological implications of hydrogen sulfide: a whiff exploration that blossomed. Physiol Rev 2012, 92:791-896.

2. Moody BF, Calvert JW: Emergent role of gasotransmitters in ischemiareperfusion injury. Med Gas Res 2011, 1:3.

3. Kimura $\mathrm{H}$ : Hydrogen sulfide: its production and functions. Exp Physiol 2011, 96:833-835.

4. Renga B: Hydrogen sulfide generation in mammals: the molecular biology of cystathionine-beta- synthase (CBS) and cystathionine-gamma -lyase (CSE). Inflamm Allergy Drug Targets 2011, 10:85-91.

5. Shibuya N, Mikami Y, Kimura Y, Nagahara N, Kimura H: Vascular endothelium expresses 3-mercaptopyruvate sulfurtransferase and produces hydrogen sulfide. J Biochem 2009, 146:623-626.

6. Shibuya N, Tanaka M, Yoshida M, Ogasawara Y, Togawa T, Ishii K, Kimura H: 3-Mercaptopyruvate sulfurtransferase produces hydrogen sulfide and bound sulfane sulfur in the brain. Antioxid Redox Signal 2009, 11:703-714

7. Streeter $E$, Hart J, Badoer $E$ : An investigation of the mechanisms of hydrogen sulfide-induced vasorelaxation in rat middle cerebral arteries. Naunyn Schmiedebergs Arch Pharmacol 2012, 385:991-1002.

8. Yang G, Wu L, Jiang B, Yang W, Qi J, Cao K, Meng Q, Mustafa AK, Mu W, Zhang $\mathrm{S}$, et al: $\mathrm{H} 2 \mathrm{~S}$ as a physiologic vasorelaxant: hypertension in mice with deletion of cystathionine gamma-lyase. Science 2008, 322:587-590.

9. Kimura H: Metabolic turnover of hydrogen sulfide. Front Physio/ 2012, 3:101.

10. Furne J, Saeed A, Levitt MD: Whole tissue hydrogen sulfide concentrations are orders of magnitude lower than presently accepted values. Am J Physiol Regul Integr Comp Physiol 2008, 295:R1479-R1485.

11. Ogasawara $Y$, Isoda S, Tanabe $S$ : Tissue and subcellular distribution of bound and acid-labile sulfur, and the enzymic capacity for sulfide production in the rat. Biol Pharm Bull 1994, 17:1535-1542.

12. Ishigami $M$, Hiraki $K$, Umemura $K$, Ogasawara $Y$, Ishii $K$, Kimura H: A source of hydrogen sulfide and a mechanism of its release in the brain. Antioxid Redox Signal 2009, 11:205-214.

13. Olson KR: Is hydrogen sulfide a circulating "gasotransmitter" in vertebrate blood? Biochim Biophys Acta 2009, 1787:856-863.

14. Carballal S, Trujillo M, Cuevasanta E, Bartesaghi S, Moller MN, Folkes LK, Garcia-Bereguiain MA, Gutierrez-Merino C, Wardman P, Denicola A, et al: Reactivity of hydrogen sulfide with peroxynitrite and other oxidants of biological interest. Free Radic Biol Med 2010, 50:196-205.

15. King SB: Potential biological chemistry of hydroge sulfide $(\mathrm{H} 2 \mathrm{~S})$ with the nitrogen oxides. Free Radic Biol Med 2013, 55:1-7.

16. Nagy $P$, Winterbourn CC: Rapid reaction of hydrogen sulfide with the neutrophil oxidant hypochlorous acid to generate polysulfides. Chem Res Toxicol 2010, 23:1541-1543.

17. Paul BD, Snyder $\mathrm{SH}: \mathrm{H}(2) \mathrm{S}$ signalling through protein sulfhydration and beyond. Nat Rev Mol Cell Biol 2012, 13:499-507.

18. Triggle CR, Samuel SM, Ravishankar S, Marei I, Arunachalam G, Ding H: The endothelium: influencing vascular smooth muscle in many ways. Can J Physiol Pharmacol 2012, 90:713-738.

19. Al-Magableh MR, Hart JL: Mechanism of vasorelaxation and role of endogenous hydrogen sulfide production in mouse aorta. Naunyn Schmiedebergs Arch Pharmacol 2011, 383:403-413.

20. Cheang WS, Wong WT, Shen B, Lau CW, Tian XY, Tsang SY, Yao X, Chen ZY, Huang $Y$ : 4-aminopyridine-sensitive $K$ + channels contributes to NaHSinduced membrane hyperpolarization and relaxation in the rat coronary artery. Vascul Pharmacol 2010, 53:94-98.
21. Lee SW, Cheng Y, Moore PK, Bian JS: Hydrogen sulphide regulates intracellular $\mathrm{pH}$ in vascular smooth muscle cells. Biochem Biophys Res Commun 2007, 358:1142-1147.

22. Kiss $L$, Deitch EA, Szabo C: Hydrogen sulfide decreases adenosine triphosphate levels in aortic rings and leads to vasorelaxation via metabolic inhibition. Life Sci 2008, 83:589-594.

23. Zhao W, Wang R: $\mathrm{H}(2) \mathrm{S}$-induced vasorelaxation and underlying cellula and molecular mechanisms. Am J Physiol Heart Circ Physiol 2002, 283: H474-H480

24. Cheng Y, Ndisang J, Tang G, Cao K, Wang R: Hydrogen sulfide-induced relaxation of resistance mesenteric artery beds of rats. Am J Physiol Heart Circ Physiol 2004, 287:2316-2323.

25. Zagli G, Patacchini R, Trevisani M, Abbate R, Cinotti S, Gensini GF, Masotti G, Geppetti P: Hydrogen sulfide inhibits human platelet aggregation. Eur J Pharmacol 2007, 559:65-68.

26. Morel A, Malinowska J, Olas B: Antioxidative properties of hydrogen sulfide may involve in its antiadhesive action on blood platelets. Clin Biochem 2012, 45:1678-1682.

27. Land WG: Emerging role of innate immunity in organ transplantation: part I: evolution of innate immunity and oxidative allograft injury. Transplant Rev (Orlando) 2012, 26:60-72.

28. Forstermann U: Oxidative stress in vascular disease: causes, defense mechanisms and potential therapies. Nat Clin Pract Cardiovasc Med 2008, 5:338-349.

29. Chen AF, Chen DD, Daiber A, Faraci FM, Li H, Rembold CM, Laher I: Free radical biology of the cardiovascular system. Clin Sci (Lond) 2012, 123:73-91.

30. MacKenzie A, Martin W: Loss of endothelium-derived nitric oxide in rabbit aorta by oxidant stress: restoration by superoxide dismutase mimetics. Br J Pharmacol 1998, 124:719-728.

31. Drummond GR, Selemidis S, Griendling KK, Sobey CG: Combating oxidative stress in vascular disease: NADPH oxidases as therapeutic targets. Nat Rev Drug Discov 2011, 10:453-471.

32. Miller AA, Drummond GR, Sobey CG: Reactive oxygen species in the cerebral circulation: are they all bad? Antioxid Redox Signal 2006, 8:1113-1120.

33. Brandes RP, Weissmann N, Schroder K: NADPH oxidases in cardiovascular disease. Free Radic Biol Med 2010, 49:687-706.

34. Stasko A, Brezova V, Zalibera M, Biskupic S, Ondrias K: Electron transfer: a primary step in the reactions of sodium hydrosulphide, an $\mathrm{H} 2 \mathrm{~S} / \mathrm{HS}(-)$ donor. Free Radic Res 2009, 43:581-593.

35. Whiteman M, Armstong J, Chu S, Jia-Ling S, Wong B, Cheung N, Halliwell B, Moore P: The novel neuromodulator hydrogen sulfide: an endogenous peroxynitrite 'scavenger'? J Neurochem 2004, 90:765-768.

36. Yan SK, Chang T, Wang H, Wu L, Wang R, Meng QH: Effects of hydrogen sulfide on homocysteine-induced oxidative stress in vascular smooth muscle cells. Biochem Biophys Res Commun 2006, 351:485-491.

37. Lu M, Hu LF, Hu G, Bian JS: Hydrogen sulfide protects astrocytes against $\mathrm{H}(2) \mathrm{O}(2)$-induced neural injury via enhancing glutamate uptake. Free Radic Biol Med 2008, 45:1705-1713.

38. Whiteman M, Cheung N, Zhu Y, Chu S, Siau J, Wong B, Armstrong J, Moore $P$ : Hydrogen sulphide: a novel inhibitor of hypochlorous acid-mediated oxidative damage in the brain? Biochem Biophys Res Commun 2005 , 343:303-310.

39. Muzaffar S, Jeremy JY, Sparatore A, Del Soldato P, Angelini GD, Shukla N: H2S-donating sildenafil (ACS6) inhibits superoxide formation and gp91phox expression in arterial endothelial cells: role of protein kinases A and G. Br J Pharmacol 2008, 155:984-994.

40. Muzaffar S, Shukla N, Bond M, Newby AC, Angelini GD, Sparatore A, Del Soldato $P$, Jeremy JY: Exogenous hydrogen sulfide inhibits superoxide formation, NOX-1 expression and Rac1 activity in human vascular smooth muscle cells. J Vasc Res 2008, 45:521-528.

41. Kimura $Y$, Goto $Y$, Kimura H: Hydrogen sulfide increases glutathione production and suppresses oxidative stress in mitochondria. Antioxid Redox Signal 2010, 12:1-13

42. Modis K, Coletta C, Erdelyi K, Papapetropoulos A, Szabo C: Intramitochondrial hydrogen sulfide production by 3-mercaptopyruvate sulfurtransferase maintains mitochondrial electron flow and supports cellular bioenergetics. FASEB J 2012, 27(2):601-611.

43. Sun WH, Liu F, Chen Y, Zhu YC: Hydrogen sulfide decreases the levels of ROS by inhibiting mitochondrial complex IV and increasing SOD activities in cardiomyocytes under ischemia/reperfusion. Biochem Biophys Res Commun 2012, 421:164-169. 
44. Suzuki K, Olah G, Modis K, Coletta C, Kulp G, Gero D, Szoleczky P, Chang T, Zhou Z, Wu L, et al: Hydrogen sulfide replacement therapy protects the vascular endothelium in hyperglycemia by preserving mitochondrial function. Proc Natl Acad Sci USA 2011, 108:13829-13834.

45. Rossoni G, Sparatore A, Tazzari V, Manfredi B, Del Soldato P, Berti F: The hydrogen sulphide-releasing derivative of diclofenac protects against ischaemia-reperfusion injury in the isolated rabbit heart. $\mathrm{Br} J$ Pharmacol 2008, 153:100-109.

46. Benetti LR, Campos D, Gurgueira SA, Vercesi AE, Guedes CE, Santos KL, Wallace JL, Teixeira SA, Florenzano J, Costa SK, et al: Hydrogen sulfide inhibits oxidative stress in lungs from allergic mice in vivo. Eur $J$ Pharmacol 2013, 698:463-469.

47. Copple IM: The Keap1-Nrf2 cell defense pathway-a promising therapeutic target? Adv Pharmacol 2012, 63:43-79.

48. Han W, Dong Z, Dimitropoulou C, Su Y: Hydrogen sulfide ameliorates tobacco smoke-induced oxidative stress and emphysema in mice. Antioxid Redox Signal 2011, 15:2121-2134.

49. Ganster F, Burban M, de la Bourdonnaye M, Fizanne L, Douay O, Loufrani L, Mercat A, Cales P, Radermacher P, Henrion D, et al: Effects of hydrogen sulfide on hemodynamics, inflammatory response and oxidative stress during resuscitated hemorrhagic shock in rats. Crit Care 2010, 14:R165.

50. Calvert JW, Elston M, Nicholson CK, Gundewar S, Jha S, Elrod JW, Ramachandran A, Lefer DJ: Genetic and pharmacologic hydrogen sulfide therapy attenuates ischemia-induced heart failure in mice. Circulation 2010, 122:11-19.

51. Li HD, Zhang ZR, Zhang QX, Qin ZC, He DM, Chen JS: Treatment with exogenous hydrogen sulfide attenuates hyperoxia-induced acute lung injury in mice. Eur J Appl Physiol 2013. in press.

52. Peake BF, Nicholson CK, Lambert JP, Hood RL, Amin H, Amin S, Calvert JW: Hydrogen sulfide preconditions the $\mathrm{db} / \mathrm{db}$ diabetic mouse heart against ischemia-reperfusion injury by activating Nrf2 signaling in an Erkdependent manner. Am J Physiol Heart Circ Physiol 2013:in press.

53. Yang G, Zhao K, Ju Y, Mani S, Cao Q, Puukila S, Khaper N, Wu L, Wang R: Hydrogen sulfide protects against cellular senescence via S-sulfhydration of Keap1 and activation of Nrf2. Antioxid Redox Signal 2013, 18:1906-1919.

54. Hourihan JM, Kenna JG, Hayes JD: The gasotransmitter hydrogen sulfide induces Nrf2-target genes by inactivating the Keap1 ubiquitin ligase substrate adaptor through formation of a disulfide bond between Cys226 and Cys-613. Antioxid Redox Signal 2013. in press.

55. Zhao W, Zhang J, Lu Y, Wang R: The vasorelaxant effect of $\mathrm{H}(2) \mathrm{S}$ as a novel endogenous gaseous K(ATP) channel opener. EMBO J 2001, 20:6008-6016

56. Yan H, Du J, Tang C: The possible role of hydrogen sulfide on the pathogenesis of spontaneous hypertension in rats. Biochem Biophys Res Commun 2004, 313:22-27.

57. Lu M, Liu YH, Goh HS, Wang JJ, Yong QC, Wang R, Bian JS: Hydrogen sulfide inhibits plasma Renin activity. J Am Soc Nephrol 2010, 21:993-1002.

58. Laggner H, Hermann M, Esterbauer H, Muellner MK, Exner M, Gmeiner BM, Kapiotis S: The novel gaseous vasorelaxant hydrogen sulfide inhibits angiotensin-converting enzyme activity of endothelial cells. $J$ Hypertens 2007, 25:2100-2104

59. Zhao X, Zhang LK, Zhang CY, Zeng XJ, Yan H, Jin HF, Tang CS, Du JB: Regulatory effect of hydrogen sulfide on vascular collagen content in spontaneously hypertensive rats. Hypertens Res 2008, 31:1619-1630.

60. Cai WJ, Wang MJ, Moore PK, Jin HM, Yao T, Zhu YC: The novel proangiogenic effect of hydrogen sulfide is dependent on Akt phosphorylation. Cardiovasc Res 2007, 76:29-40.

61. Papapetropoulos A, Pyriochou A, Altaany Z, Yang G, Marazioti A, Zhou Z, Jeschke MG, Branski LK, Herndon DN, Wang R, Szabo C: Hydrogen sulfide is an endogenous stimulator of angiogenesis. Proc Natl Acad Sci USA 2009, 106:21972-21977.

62. Wang MJ, Cai WJ, Li N, Ding YJ, Chen Y, Zhu YC: The hydrogen sulfide donor NaHS promotes angiogenesis in a rat model of hind limb ischemia. Antioxid Redox Signal 2010, 12:1065-1077.

63. Weber $\mathrm{C}$, Noels $\mathrm{H}$ : Atherosclerosis: current pathogenesis and therapeutic options. Nat Med 2011, 17:1410-1422.

64. Judkins CP, Diep H, Broughton BR, Mast AE, Hooker EU, Miller AA, Selemidis S, Dusting GJ, Sobey CG, Drummond GR: Direct evidence of a role for Nox2 in superoxide production, reduced nitric oxide bioavailability, and early atherosclerotic plaque formation in ApoE-/- mice. Am J Physiol Heart Circ Physiol 2010, 298:H24-H32.
65. Lynn EG, Austin RC: Hydrogen sulfide in the pathogenesis of atherosclerosis and its therapeutic potential. Expert Rev Clin Pharmacol 2011, 4:97-108.

66. Whiteman $M$, Li L, Rose $P$, Tan $C H$, Parkinson D, Moore P: The effect of hydrogen sulfide donors on lipopolysaccharide-induced formation of inflammatory mediators in macrophages. Antioxid Redox Signal 2010, 12(10):1147-54.

67. Zhang H, Guo C, Wu D, Zhang A, Gu T, Wang L, Wang C: Hydrogen sulfide inhibits the development of atherosclerosis with suppressing CX3CR1 and CX3CL1 expression. PLoS One 2012, 7:e41147.

68. Zanardo RC, Brancaleone V, Distrutti E, Fiorucci S, Cirino G, Wallace JL: Hydrogen sulfide is an endogenous modulator of leukocyte-mediated inflammation. FASEB J 2006, 20:2118-2120.

69. Wang $Y$, Zhao X, Jin H, Wei H, Li W, Bu D, Tang X, Ren Y, Tang C, Du J: Role of hydrogen sulfide in the development of atherosclerotic lesions in apolipoprotein E knockout mice. Arterioscler Thromb Vasc Biol 2009 29:173-179.

70. Mestas J, Ley K: Monocyte-endothelial cell interactions in the development of atherosclerosis. Trends Cardiovasc Med 2008, 18:228-232.

71. Laggner H, Muellner MK, Schreier S, Sturm B, Hermann M, Exner M, Gmeiner BM, Kapiotis S: Hydrogen sulphide: a novel physiological inhibitor of LDL atherogenic modification by $\mathrm{HOCl}$. Free Radic Res 2007, 41:741-747.

72. Zhao ZZ, Wang Z, Li GH, Wang R, Tan JM, Cao X, Suo R, Jiang ZS: Hydrogen sulfide inhibits macrophage-derived foam cell formation. Exp Biol Med (Maywood) 2011, 236:169-176.

73. Meng Q, Yang G, Yang W, Jiang B, Wu L, Wang R: Protective effect of hydrogen sulfide on balloon injury-induced neointima hyperplasia in rat carotid arteries. Am J Pathol 2007, 170:1406-1414.

74. Du J, Hui $Y$, Cheung $Y$, Bin $G$, Jiang $H$, Chen $X$, Tang $C$ : The possible role of hydrogen sulfide as a smooth muscle cell proliferation inhibitor in rat cultured cells. Hear Vessel 2004, 19:75-80.

75. Yang G, Sun X, Wang R: Hydrogen sulfide-induced apoptosis of human aorta smooth muscle cells via the activation of mitogen-activated protein kinases and caspase-3. FASEB J 2004, 18:1782-1784.

76. Yang G, Cao K, Wu L, Wang R: Cystathionine gamma-lyase overexpression inhibits cell proliferation via a H2S-dependent modulation of ERK1/2 phosphorylation and p21Cip/WAK-1. J Biol Chem 2004, 279:49199-49205.

77. Yang G, Li H, Tang G, Wu L, Zhao K, Cao Q, Xu C, Wang R: Increased neointimal formation in cystathionine gamma-lyase deficient mice: role of hydrogen sulfide in alpha5beta1-integrin and matrix metalloproteinase-2 expression in smooth muscle cells. J Mol Cell Cardiol 2012, 52:677-688

78. Zavaczki E, Jeney V, Agarwal A, Zarjou A, Oros M, Katko M, Varga Z, Balla G, Balla J: Hydrogen sulfide inhibits the calcification and osteoblastic differentiation of vascular smooth muscle cells. Kidney Int 2011, 80:731-739.

79. Wu SY, Pan CS, Geng B, Zhao J, Yu F, Pang YZ, Tang CS, Qi YF: Hydrogen sulfide ameliorates vascular calcification induced by vitamin D3 plus nicotine in rats. Acta Pharmacol Sin 2006, 27:299-306.

80. Jain SK, Micinski D, Lieblong BJ, Stapleton T: Relationship between hydrogen sulfide levels and HDL-cholesterol, adiponectin, and potassium levels in the blood of healthy subjects. Atherosclerosis 2012, 225:242-245.

81. Jain SK, Bull R, Rains JL, Bass PF, Levine SN, Reddy S, McVie R, Bocchini JA: Low levels of hydrogen sulfide in the blood of diabetes patients and streptozotocin-treated rats causes vascular inflammation? Antioxid Redox Signal 2010, 12:1333-1337.

doi:10.1186/2045-9912-3-9

Cite this article as: Streeter et al:: Hydrogen sulfide as a vasculoprotective factor. Medical Gas Research 2013 3:9. 